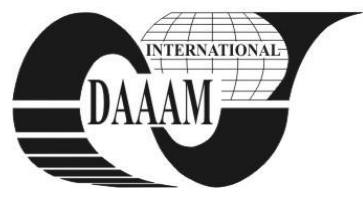

Annals of DAAAM for 2011 \& Proceedings of the 22nd International DAAAM Symposium, Volume 22, No. 1, ISSN 1726-9679 ISBN 978-3-901509-83-4, Editor B. Katalinic, Published by DAAAM International, Vienna, Austria, EU, 2011 Make Harmony between Technology and Nature, and Your Mind will Fly Free as a Bird

Annals \& Proceedings of DAAAM International 2011

\title{
ALVEOGRAPH AS A RHEOLOGICAL TOOL TO PREDICT THE QUALITY CHARACTERISTICS OF WHEAT FLOUR
}

\author{
CODINA, G[eorgiana] - G[abriela]; GUTT, S[onia]; GUTT, G[heorghe] \& MIRONEASA, S[ilvia]
}

\begin{abstract}
Studies were carried out on seventeen samples of Romanian wheat flour to assess the relationship between viscoelastic parameters specific to the Alveograph method and flour analytical parameters (moisture content, wet gluten content, gluten deformation index, ash content, falling number index). Our results were included into a mathematical simulation, in order to elaborate predictive models for estimating the value of the analytical parameters of wheat flour based on Alveograph rheological characteristics. Three predictive multifactorial models were developed for wet gluten content, gluten deformation index and falling number index.

Key words: alveograph device, rheological properties, predictive model, flour quality
\end{abstract}

\section{INTRODUCTION}

The rheological characterization of wheat flour dough is essential in bakery industry. Traditional dough testing instruments such as Farinograph, Mixograph, Alveograph, Extensigraph, Mixograph, Amylograph, Maturograph, etc., have become important tests to asses and predict the quality of the finished bakery products (Mirsaeedghazi et al., 2008). In Romania, the most common rheological dough testing instrument is the Alveograph (Chopin, France) which describes dough behaviour to extension. It measures the flexibility of the dough sample produced from the flour, water and salt by inflating a dough bubble under the effect of air pressure in a thin sheet until it bursts. The resulting values show the baking strength of the flour in terms of tenacity, extensibility, elasticity and thus its suitability for different uses. Some studies were conducted on the use of the Alveograph to determine the quality of wheat flour in terms of the analytical characteristics (Codină et al., 2010; Popa et al., 2009; Hrušková \& Šmejda, 2003; Miralbés, 2003; Bettge et al., 1989). Because in Romania most of the cereal laboratories are used in order to evaluate the wheat flour quality of some analytical parameters like wet gluten content (WG), gluten deformation index (GDI), falling number index (FN), ash content (Ash) and moisture content (MO), we thought it would be useful if we tried to establish a series of correlations between these analytical parameters and the Alveograph parameters curve on a range of Romanian white wheat flour in order to establish some predictive models for evaluating the analytical parameters, as a function of rheological values.

\section{EXPERIMENTAL RESEARCH}

Seventeen samples of different commercial wheat flours were obtained from different milling companies. The characteristics of the sample, the means and range with abbreviated names are given in Table 1. The chemical composition of the flours was determined according to Romanian or international standard methods: moisture content (ICC-Standard Method No. 110/1), wet gluten content (ICCStandard Method No. 106/1), gluten deformation index (SRNo. 90), ash content (ICC-Standard Method No. 104/1), falling number index (ICC- Standard Method No. 107/1).
The rheological properties of wheat flour dough were determined by the Alveograph device (Table 2) according to SR EN ISO 27971: 2008. Each Alveograph chart was analyzed for parameters: $\mathrm{P}$ - the maximum over pressure needed to blow the dough bubble, expresses dough resistance, $\mathrm{L}-$ the length of the curve, expresses dough extensibility, $\mathrm{P} / \mathrm{L}-$ the configuration ratio of the Alveograph curve, $\mathrm{G}$ - index of swelling, W - baking strength (surface area of the curve), Ie elasticity index.

All the measurements were done in triplicates. The results were processed and statistically interpreted by using SPSS statistical package program. The final model will remember the smallest number of variables, with the highest contribution to predict the criterion. The selected independent values optimally explain the criterion variation. Building the model through the backward method begins with all the variables considered in the model, and at each step the least significant predicator is eliminated - the independent value of less importance, the value which determines the smallest reduction of the Fisher statistic, $F$. Variables are eliminated up to a level of significance, previously established, which for the $F$ is no longer reached. A significance level of 0.05 was chosen. The equation of multiple regression (Eq. 1) contains predictors' values $(\mathrm{W}, \mathrm{P}, \mathrm{L}$ and $\mathrm{P} / \mathrm{L})$ and the coefficients $b_{i}, i=0 \ldots 4$, which are calculated based on the correlation coefficient between each predictor and criterion (WG, GDI, respectively FN).

$$
Y^{\prime}=b_{o}+b_{1} \cdot X_{1}+b_{2} \cdot X_{2}+b_{3} \cdot X_{3}+b_{4} \cdot X_{4}
$$

$Y^{\prime}$ represents the estimated value for the criterion variable; $b_{0}$ constant value; $b_{1}, b_{2}, b_{3}, b_{4}$ - regression coefficients; $X_{1}, X_{2}$, $\mathrm{X}_{3}, \mathrm{X}_{4}$ - the values of the predictor variables: $\mathrm{X}_{1}=$ baking strength $(\mathrm{W})\left[10^{-4} \mathrm{~J}\right] ; \mathrm{X}_{2}=\operatorname{dough}$ tenacity $(\mathrm{P})[\mathrm{mm}] ; \mathrm{X}_{3}=$ dough extensibility $(\mathrm{L})[\mathrm{mm}] ; \mathrm{X}_{4}=$ configuration ratio of the Alveograph curve $(\mathrm{P} / \mathrm{L})$.

The values correlation coefficients between technological characteristics of wheat flour dough and Alveograph parameters curve show that it is possible to achieve a predictive model.

From the point of view of WG, there is a high significant correlation $(\mathrm{p}=0.01)$ between this parameter and GDI $(\mathrm{r}=$ 0.519 , Ash $(\mathrm{r}=0.339), \mathrm{W}(\mathrm{r}=0.429), \mathrm{P}(\mathrm{r}=0.493)$ and a significant correlation $(\mathrm{p}=0.05)$ with $\mathrm{L}(\mathrm{r}=-0.268), \mathrm{G}(\mathrm{r}=$ $0.242)$ and $\mathrm{P} / \mathrm{L}(\mathrm{r}=0.301)$.

Flours with a higher content of wet gluten (WG) will produce a more developed glutenic network, which will realize a better distribution of dough ingredients. Thus, the strength to the extension of dough under Alveograph effect of air pressure will be higher. That way, the increase of flour wet gluten content will determine, in relation to the Alveograph rheological parameters curve, an increase of $\mathrm{P}$, a decrease of $\mathrm{L}$ and $\mathrm{G}$ values and an increase of W. The results obtained (Eq.2) show that the best predictors, the independent values that estimate with the highest precision the WG criterion, are the 
parameters $\mathrm{W}, \mathrm{P}$ and $\mathrm{P} / \mathrm{L}$, the contribution of the three variables being significant.

The value of multiple correlation coefficient is $\mathrm{R}=0.68$.

\begin{tabular}{|l|c|c|c|c|c|}
\hline \multicolumn{1}{|c|}{ Parameters } & \multirow{2}{*}{$\begin{array}{c}\text { Abbreviated } \\
\text { name }\end{array}$} & Mean & \multicolumn{2}{|c|}{ Range } & Std. \\
\cline { 4 - 5 } & MO & 14.58 & 12.90 & 15.90 & 0.32 \\
\hline $\begin{array}{l}\text { Moisture } \\
\text { content [\%] }\end{array}$ & WG & 26.60 & 23.80 & 28.40 & 1.12 \\
\hline $\begin{array}{l}\text { Wet gluten } \\
\text { content [\%] }\end{array}$ & GDI & 6.53 & 4.00 & 17.00 & 2.46 \\
\hline $\begin{array}{l}\text { Gluten } \\
\text { deformation } \\
\text { index [mm] }\end{array}$ & Ash & 0.63 & 0.41 & 0.68 & 0.04 \\
\hline Ash content [\%] & FN & 289.55 & 251.00 & 450.00 & 40.30 \\
\hline $\begin{array}{l}\text { Falling Number } \\
\text { index [s] }\end{array}$ & FN & & & & \\
\hline
\end{tabular}

Tab 1. Flour analytical parameters

\begin{tabular}{|l|c|c|c|c|c|}
\hline \multirow{2}{*}{ Parameters } & \multirow{2}{*}{$\begin{array}{c}\text { Abbreviate } \\
\text { name }\end{array}$} & \multirow{2}{*}{ Mean } & \multicolumn{2}{|c|}{ Range } & Std. \\
\cline { 4 - 5 } & & min. & max. & dev. \\
\hline Tenacity [mm] & $\mathrm{P}$ & 93.98 & 56.00 & 150.00 & 19.49 \\
\hline $\begin{array}{l}\text { Extensibility } \\
{[\mathrm{mm}]}\end{array}$ & $\mathrm{L}$ & 76.10 & 45.00 & 116.00 & 12.54 \\
\hline $\begin{array}{l}\text { Index of } \\
\text { swelling [mm] }\end{array}$ & $\mathrm{G}$ & 19.35 & 14.90 & 24.00 & 1.60 \\
\hline $\begin{array}{l}\text { Baking strength } \\
{\left[10^{-4} \mathrm{~J}\right]}\end{array}$ & $\mathrm{W}$ & 240.46 & 168.00 & 419.00 & 45.24 \\
\hline $\begin{array}{l}\text { Configuration } \\
\text { ratio }\end{array}$ & $\mathrm{P} / \mathrm{L}$ & 1.29 & 0.50 & 3.33 & 0.45 \\
\hline $\begin{array}{l}\text { Elasticity index } \\
{[\%]}\end{array}$ & $\mathrm{Ie}$ & 52.88 & 41.90 & 63.20 & 4.58 \\
\hline
\end{tabular}

Tab 2. Alveograph rheological parameters of flour samples

$\mathrm{WG}=22.819+(-0.028) \cdot \mathrm{W}+0.18 \cdot \mathrm{P}+(-4.935) \cdot \mathrm{P} / \mathrm{L}$

The value coefficient of determination $\left(\mathrm{R}^{2}=0.46\right)$ shows that $46 \%$ of the variance of the WG is applied to the linear combination of $\mathrm{W}, \mathrm{P}$ and $\mathrm{P} / \mathrm{L}$ variables, the global effect having a high level.

The gluten deformation index (GDI) is one of the most widely used parameters in Romania to evaluate the quality of wheat flour. The determination of this parameter is very advantageous because it provides information on both the quality and quantity of WG (between these parameters, the correlation is highly significant: $r=$ $0.519, \mathrm{p}=0.01$ ). GDI can describe if flour gluten is easily deformed (weak flour) and extensible without returning to its original shape (plastic) or if flour gluten can only be extended (elastic) by applying a considerable force (strong flour). Wheat GDI gave high significant correlation $(\mathrm{p}=0.01)$ with Alveograph parameters curve like $\mathrm{L}(\mathrm{r}=$ $0.505), \mathrm{G}(\mathrm{r}=0.484), \mathrm{P}(\mathrm{r}=-0.479)$ and significant correlation $(\mathrm{p}=$ $0.05)$ with $\mathrm{P} / \mathrm{L}(\mathrm{r}=-0.433)$ and $\mathrm{W}(\mathrm{r}=-0.273)$. Therefore, the Alveograph device allows the measurement of GDI. Its mode of deformation is similar to the extension that takes place during fermentation and oven rise. That is why the GDI is inverse correlated with parameters $\mathrm{P}, \mathrm{P} / \mathrm{L}$ and $\mathrm{W}$ and direct, correlated with $\mathrm{L}$ and $\mathrm{G}$. The best model for GDI, from the point of view of the coefficient of determination $\left(\mathrm{R}^{2}=0.41\right)$ and significance of coefficients of variables ( $\mathrm{p} \leq 0.001$ ), uses the predictors $\mathrm{P}, \mathrm{L}$ and $\mathrm{P} / \mathrm{L}$ (Eq.3). The correlation coefficient multiple is $\mathrm{R}=0.636$. That model explains $41 \%$ of the variation of the GDI, the global effect having a medium level.

$$
\mathrm{GDI}=(-4.058)+(-0.122) \cdot \mathrm{P}+0.179 \cdot \mathrm{L}+6.541 \cdot \mathrm{P} / \mathrm{L}
$$

The content of falling number index $(\mathrm{FN})$ in the flour has correlated high significant positive $(\mathrm{p}=0.01)$ with $\mathrm{P}(\mathrm{r}=$ $0.459), W(r=0.360), P / L(r=0.449)$, and significant negative correlated $(p=0.05)$ with $G(r=-0.242)$. Thus, in the flour with a low alpha-amylase activity, the resistance of the dough is higher and the $\mathrm{L}$ is lower. Such a weakening tendency of the dough for flours with low FN values could be attributed to the presence of a low molecular weight dextrin produced by hydrolyses of damaged starch. The best mathematical simulations for the regression, between the values $\mathrm{FN}$ of the flours and the Alveograph parameters are the following (Eq.4):

$$
\mathrm{FN}=41.527+1.838 \cdot \mathrm{L}+83.413 \cdot \mathrm{P} / \mathrm{L}
$$

where the correlation coefficient multiple is $\mathrm{R}=0.542$. The value $\mathrm{R}^{2}$ $=0.30$ shows that model explains $30 \%$ of the variation of the $\mathrm{FN}$, the global effect having a medium level.

The value obtained for the Durbin-Watson test for each of the three models $(1.824 ; 1.406 ; 1.799)$ shows that the condition for independence of errors is respected. As the value of the statistical significance of $\mathrm{F}$ is small ( $\mathrm{p}<0.0001)$, it can be concluded that models (3), (4), (5) are significant, the $\mathrm{W}, \mathrm{P}, \mathrm{L}$ and $\mathrm{P} / \mathrm{L}$ rheological parameters offering the best explanation of the variation of the same analytical parameters of wheat flour.

Regarding the correlation between the moisture and ash content with the specific values of the rheological Alveograph parameters. we noticed very little significant relations. That is why we can conclude that these parameters have an insignificant importance for the Alveograph's viscoelastic characteristics of dough, maybe because wheat flour used in our experimental research belongs to the same type regarding ash content (0.63 mean).

\section{CONCLUSIONS}

The models obtained for wet gluten content (WG), gluten deformation index (GDI) and falling number index (FN) are significant and offer a high level of predictability. For this reason we believe that Alveograph rheological parameters can be used in evaluating the quality of wheat flour.

The analysis of the predictive models obtained can conclude the following: 1) wet gluten content can be modelled based on W, P and P/L Alveograph rheological paramteres; 2) the best predictors for the gluten deformation index are $\mathrm{P}, \mathrm{L}$ and $\mathrm{P} / \mathrm{L}$ values; 3 ) simulation of parameter falling number index is given by $\mathrm{L}$ and $\mathrm{P} / \mathrm{L}$ Alveograph values.

In our future studies, we want to establish other predictive models to estimate the values of the Alveograph rheological parameters of wheat flour based on the wheat flour analytical characteristics. We consider that both these studies (the present and the future one) will be extremely useful for the workers in the bakery industry and not only.

\section{REFERENCES}

Bettge, A., Rubenthaler G.L. \& Pomeranz, Y. (1989). Alveograph algorithms to predict functional properties of wheat in bread and cookie baking, Cereal Chemistry, No. 66, 81-86, ISSN 0009-0352

Codină, G.G., Mironeasa, S., Bordei, D. \& Leahu, A. (2010). Mixolab versus Alveograph and Falling Number, Czech J. of Food Sciences, No. 28, 185-191, ISSN 1212-1800

Hrušková, M. \& Šmejda, P. (2003). Wheat flour dough alveograph characteristics predicted by NIR systems 6500 , Czech J. of Food Sciences, No. 21, 28-33, ISSN 1212-1800

Miralbés, C. (2003). Prediction chemical composition and alveograph parameters on wheat by near-infrared transmittance spectroscopy, J. of Agriculture and Food Chemistry, No. 51, 6335-6339, ISSN 0021-8561

Mirsaeedghazi, H., Emam-Djomeh, Z. \& Mousavi, S.M.A. (2008). Rheometric measurement of dough rheological characteristics and factors affecting it, Int. J. of Agric. and Biology, No. 10, 112-119, ISSN 1814-9596

Popa, N.C., Tamba-Berhoiu, R., Popescu, C., Varga, M. \& Codină, G.G. (2009). Predictive model of the alveografic parameters in flours obtained from Roumanian grains, Roumanian Biotechnological Letters, No. 14, 4234 - 4242, ISSN 1224-5984 